\title{
Editorial: De-normalizing the Normal
}

\author{
SILVIJA JESTROVIC
}

What was the last show you saw before the pandemic made theatres go dark? What is the first theatre outing you have been to as theatres (at least in some parts of the world) have started to reopen?

It is November 2019, and we are in London - two of my oldest childhood friends, our children and I - making ourselves comfortable in the packed auditorium of the National Theatre as the performance of Athol Fugard's Master Harold and the Boys is about to begin. Just before the lights go down one of the children rattles a bag of candy, and we take turns to quickly dip our fingers into the bag to grab one last sweet as the lights dim and the auditorium falls silent in anticipation. When the show ends my friend, deeply moved by the performance, still has tears in her eyes, while the children compete to share their knowledge of South Africa during the apartheid. What strikes us most, we agree, as we gently push through the crowd towards the café, is the normalization of subjugation and the damage it does to everybody children and adults, masters and servants. Once in the café, we taste each other's cakes and take a group selfie - eight of us squeezed next to each other in a café full of people. That was my last pre-pandemic theatre outing. Looking back at that photo, the first thing I see is not how beautiful and grown-up our children have become, nor how radiant our post-show smiles are, but how close together we are seated, almost entangled, I note with a tinge of alarm.

We are ushered down the gravel path stretching along the banks of the river Avon, towards the Lydia and Manfred Gorvy Garden Theatre - the Royal Shakespeare Company's temporary performance space for the summer of 2021. Tickets for Shakespeare's Comedy of Errors clutched in our hands, masks on our faces, hand sanitizers in our pockets, my daughter and I find our seats. There is nobody next to us and this is deliberate - the show is sold out, but the theatre is at half-capacity to observe social distancing. Open air above us, strangers at safe distance, and a light breeze whisking into the sky any stray droplets that might be headed our way. Our first theatre outing in over a year is confirmed low-risk, and I silently commend the RSC on their COVID safety protocols and relax into my seat - the show can now begin! I laugh at the jokes and physical comedy (even at those I wouldn't normally find that funny), I applaud the actors' labour and artistry (with greater intensity than ever), I join the rest of the audience in standing ovations (when I would normally give prevalence to critical refixation and moderate clapping). I'm not interested in what worked well in the show and what didn't, I don't want to probe or problematize, I don't want to analyse or critique, all I want to do is applaud just a little longer to the theatre-makers and to us, the audience - for making the curtain go up tonight. 'I so 


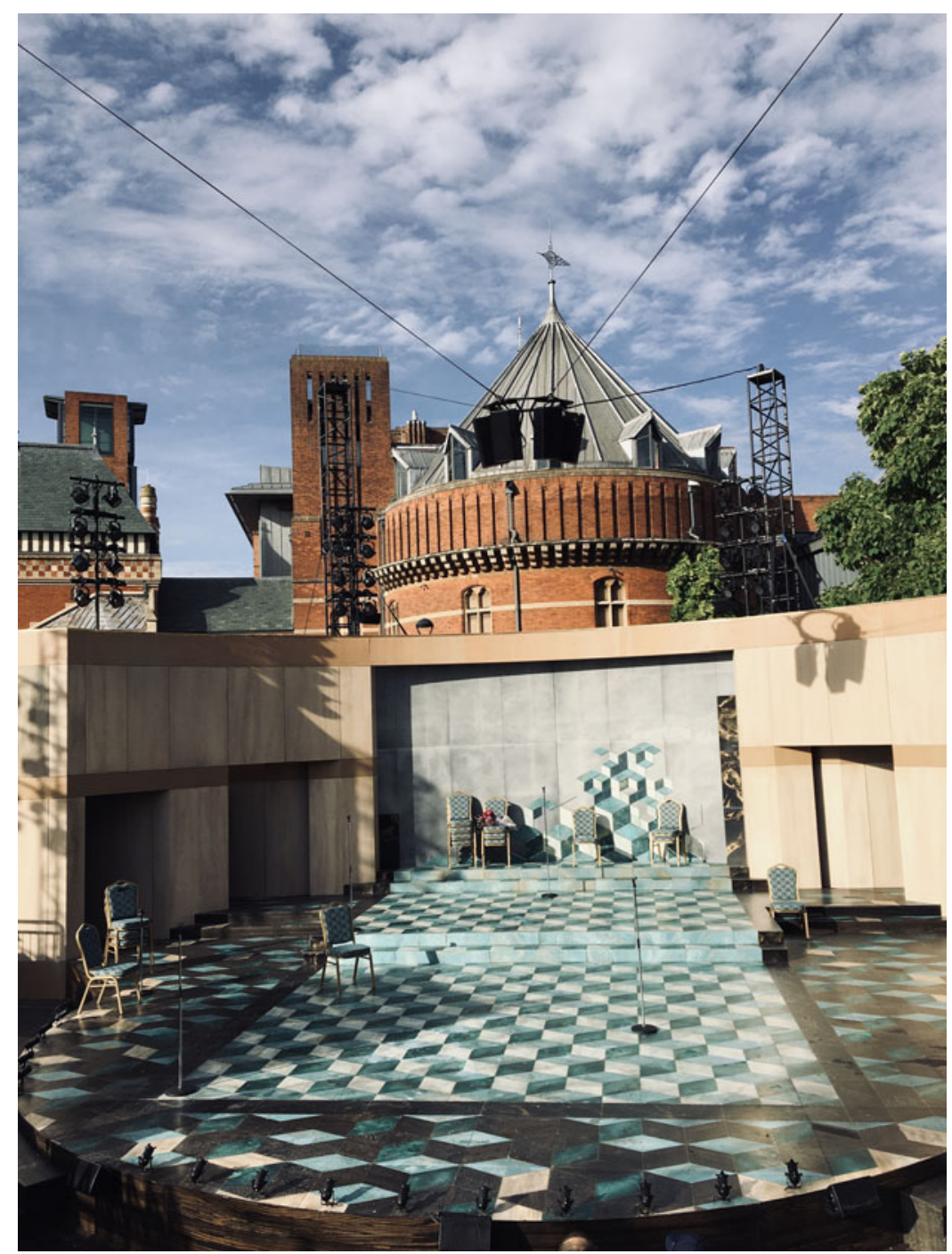

FIG. 1 Comedy of Errors set, Royal Shakespeare Company, Stratford-upon-Avon, 2021. Photograph by Silvija Jestrovic.

missed this', says my daughter; I concur, and that is the end of my first post-lockdown theatre outing. At its very beginning, just before the first actors entered, I took a photo of the bare stage, capturing what has always been there - the 'empty space' of endless possibility (Fig. 1).

Shortly after my first post-lockdown evening in theatre, British prime minister Boris Johnson proclaimed 'Freedom Day' - no more COVID restrictions, no more masks, no more social distancing, no more government responsibility - all kinds of shows, events and mass spectacles can and must go on. The numbers of COVID cases 
in the UK are soaring, as this editorial is being written, yet the public mood seems paradoxical - growing anxiety, fear and anger, on the one hand; on the other, a hunger to meet, congregate, huddle close to strangers in cafés, theatres, on public transport, pretending that the pandemic is over. At times it feels like an almost absurd suspension of belief, despite the all-permeating crisis which we live and breathe, not just of the pandemic, but of all the rest - Brexit, climate emergency, violence against women, everyday racism and xenophobia, culture wars and actual wars, never-ending refugee crises and much more. In search of both reckoning and escapism, I book more theatre tickets. The first show gets cancelled as a cast member tests positive for COVID; the second is postponed as COVID too hinders the rehearsal timetable; the third, Philip Glass's opera Satyagraha, goes on and I go to see it.

A lively discussion ensues after the show, and later with friends on social media, and with colleagues in post-Zoom-meeting chats. Since its first performance in 1980, many of my colleagues and friends had seen Satyagraha in different years, places and productions, yet the opera quickly becomes our shared experience. We talk Gandhi the complex political figure and Gandhi the sanctified political myth. We agree, we disagree, we discuss aesthetization and engagement, we discuss ways of seeing and our different geographical and cultural vantage points ... We share resources on the subject - Tolstoy's letters to Gandhi, Arundhati Roy on 'Gandhi and Ambedkar', and Judith Butler's new book Forces of Nonviolence. We all love Gandhi's final aria, we agree; we marvel at Philip McDermott's (Improbable Theatre Company) direction and Julian Crouch's design in the scene when sheets of newspaper turn into giant puppets as the demarcation between lifeless and alive onstage becomes porous, and we disagree again ... We are back to normal, to challenging and inspiring one another, to seeing live theatre, to being an international community bound together by shared experiences of making, seeing and analysing performance. This is how it should be, how it always was.

Only it isn't quite so, I realize, as sounds and images of Satyagraha slowly fold into my memory. In the foreground, together with the set, the performers and the orchestra and at times even overshadowing what was taking place onstage - were other audience members: the couple seated next to me and my sense of relief at the sight of them wearing masks; and, as the newspaper sheets were shifting shape to become the giant puppets, the person in front of me whose muffled coughs seeped into Glass's meditative musical patterns. By the final aria, sung gently in Sanskrit, her plastic hairclip, bouncing slightly with her every stifled sneeze, clawed its way into the opera's mise en scène the woman's barely audible coughing a coda to Glass's score.

Has the pandemic been altering our theatre-going rituals and ways of seeing? Has the risk of contamination overshadowed all the other risks of live performance? Have the parameters of audience responsibility and even solidarity been shifting? Do we remember and reflect on performance as we used to?

'New normal' is not the answer I am looking for. Indeed, I strongly dislike the phrase as a lazy, complacent response to the crisis and confusions of our times. Rather, I seek the answer in the myriad ways in which theatre exercises its endless capacity to make the familiar strange - to de-normalize the normal (new and old). 
Normal assumes acceptance of the norm - social, political, aesthetic, quotidian without questioning its structures, practices and consequences. Theatre has never done 'normal' very well (or at least never consistently), but it has, at its best (and even perhaps at its average), been able to reveal that what is 'out of joint' - sometimes through dramatic texts and staging, at other times through actors' improvisation, and at yet others through reactions and rituals performed in the auditorium.

The essays in this issue variously point to this capacity of theatre to grapple with times 'out of joint' in exploring crisis, political injustice, memory and new ways of seeing the past and the present. Foregrounding the links between climate crisis and colonialism, Denise Varney's essay, developed from her International Federation for Theatre Research 2021 keynote address, 'Caught in the Anthropocene: Theatres of Trees, Place and Politics', examines interrelations between the human and the non-human Other. She points to the theatricality of the Curtain Tree in the rainforests of north Queensland, linking it both directly and metaphorically to the theatrical curtain (in which post-lockdown raising we have revelled). Unlike the stage curtain, though, the performativity of the Curtain Tree unfolds even if there is no us to look on. In Varney's analysis, displacement, as a marker and embodiment of crisis, emerges in a dystopic futuristic trope of climate refugees in the dance piece by the Australian indigenous Marrugeku company. In her 'Whose Crisis? Syrian Refugees and the Turkish Stage', Emine Fişek also examines the refugee crisis, albeit in the present moment. She explores how the European refugee crisis translates to another stage and context. Through theatre, Fişek searches for a possibility of transnational aesthetics of resistance to anti-immigration politics. On a broader level, both Fişek and Varney explore the capacity of theatre and performance to offer new ways of seeing. In Fişek's essay, the crisis itself is understood historically and politically as a particular and context-specific way of seeing, 'where it can both foreclose and ultimately produce local meaning-making'. For Varney, the theatrical stage becomes the site of changed perspective - both 'familiar and estranged' - as the focus shifts 'from the human to the non-human'.

Juan Manuel Aldape Muñoz's essay 'Forensic Performances: Searching for Justice in NAKA Dance Theater's BUSCARTE: Duet' explores the intersection of theatrical performance and the claim for social justices in instances 'where the official legalscientific terrain has failed to protect victims of state repression'. Forensic performance, in this context, reveals what the state has attempted to hide - the bodies it has literally buried under the ground - the human remains of its victims, the forty-three students from Ayotzinapa Rural Teachers' College, forcibly disappeared in Iguala, Guerrero, Mexico, in 2014. The forensic dance performance Duet thus offers a way of seeing the uncanny double of a seemingly democratic state. Aldape Muñoz's case study also implies the idea of performance and risk - not the risk of contamination (encountered earlier in this editorial), but the risk of speaking through theatrical embodiment of what is too dangerous to speak about in other spheres.

Political memory and how theatre performs it is the common denominator of both Aldape Muñoz's piece and Katia Arfara's 'Unlearning History: Mark Teh and the Spectres of Baling' as both explore remains: both actual and metaphorical. In the 
former, forensic performance provides a body of evidence of a traumatic memory amounting to a form of social activism, while the latter explores the form of documentary theatre as a means of social change by questioning the role of historical memory and the archive in solidifying national identity. Focusing on Mark Teh's theatrical investigation of the 1955 Baling talks, the attempt to end the state of emergency and negotiate peace between the British colonial government and the Malayan Communist Party, Arfara explores how the figure of the party's secretary general, Chin Peng, is rescued from historical commodification and reintroduced into the public sphere as 'a spectre' through which history could be unlearned. Through analysis of Teh's performance devices, Arfara calls for the destabilizing of any fixed memory to question 'state-driven models of the authorship and ownership of history'.

Even though their examinations of history have very different focal points, both Arfara and Lotte Schüßler engage with theatre's capacity for enabling new ways of learning and unlearning. In the case of the former, the audience is engaged in a 'complex seeing' exercises through which the contradictions of collective memory are laid bare, while the latter explores the notion of Anschauung - immediate and sensual manners of perception' - understood as a key concept to measure knowledge transfers through different media. Schüßler takes us to large-scale theatre exhibitions in Vienna (1892), Berlin (1910) and Magdeburg (1927), featuring displays of German-language theatre history to explore the correlation between curatorial forms and knowledge transfer. The concept of Anschauung, debates and different modes of its interpretation, have been central to Schüßler's historical analysis of the exhibits as well as to the understanding of hermeneutical practices of spectatorship in the nineteenth century. However, the link between Anschauung and theatre as derived from théatron - viewing place - that Schüßler refers to as well, suggests an intrinsic causality between what we see and how we see it. A viewing place is also always a vantage point (physical and mental), which at times becomes altered in the process of Anschauung - and while risking decontextualizing a historical concept, we might add that this is where both the learning and the unlearning through theatre take place.

This is the first issue of Theatre Research International that Lisa Fitzpatrick, Nesreen N. Hussein and I are signing as associate editor, assistant editor and senior editor respectively. As we are starting our tenure, we also wish a warm welcome to our new editorial board and our new Asia Pacific book editor, Nobuko Anan. However, this issue is very much a product of the work of our predecessors too, most notably Fintan Walsh as senior editor and Tanya Dean as assistant editor - not only had they been directly involved in the processes of acquiring and developing some of the pieces featured in this issue, but they have also supported us patiently and wholeheartedly through the entire transition period. This issue is truly shared between our two editorial teams.

I would like to conclude my first TRI editorial with one last cultural event, not of theatre strictly speaking, but certainly of performance in its broader sense - the 2021 Turner Prize shortlist. On show in Coventry's Herbert Art Gallery and Museum, for the first time in the history of the Turner Prize, the shortlist comprises art collectives rather than individual artists. The works, which include installations, films, 
art-in-the-community and sound art, have the following in common: social engagement, a search for new inclusive ways of making and seeing art and solidarity. I think of this journal (including its place within the International Federation for Theatre Research) as being part of a research collective stretching across the globe yet held together through the shared experiences of theatre and performance. In this collective, we challenge, inspire, and support one another. Always seeking new ways of doing, seeing and thinking theatre - in these times 'out of joint' - together, we de-normalize the normal. 